\title{
TELMO HERRERA: NOVELA EN SOLITARIO
}

\author{
POR \\ MANUEL CORRALES PASCUAL \\ Pontificia Universidad Católica del Ecuador, Quito
}

\section{BREVE HISTORIA DE UN DESCONOCIDO}

E1 texto que voy a comentar es un desconocido, como casi desconocido es su autor, incluso en el Ecuador: Telmo Herrera, nacido en 1948, dejó su patria y navegó por aquí y por allá - por esos mundos- a comienzos de los años setenta. En 1973 echó anclas en París, y allí está desde entonces dedicado a escribir poemas y relatos y a dirigir y hacer teatro. En la lista de «jóvenes» escritores ecuatorianos que comienzan a darse a conocer después del 68 no figuraba el nombre de Telmo Herrera.

Sorpresivamente, en 1985, se comienza a inquirir por él a causa de una nota aparecida en un diario quiteño: en ella se dice que Telmo Herrera, ecuatoriano, ha quedado finalista en el Premio «Nadal» de Barcelona (España), en 1984. La novela que lo ha puesto tan cerca de este galardón se titula Papá murió hoy. La publicó Ediciones Destino, de Barcelona, con el número 586 de su colección «Ancora y Delfín».

Quizá sea ésta la circunstancia que me movió a elegir la novela de Telmo Herrera y no otro texto de los publicados en el Ecuador en los últimos años. La elección de un texto poético para su análisis y crítica tiene mucho de arbitraria. Si preguntamos a los analistas y a los semiólogos por qué han comentado un poema y no otro, por qué han dedicado largos estudios a tal o cual autor, no siempre - quizá casi nunca- nos darán una razón convincente intrínseca al hecho poético. Por otra parte, el haber estado muy cerca de un prestigioso premio literario no es necesariamente signo de excepcional calidad poética. Pero sí puede ser esta circunstancia una apertura de posibilidades más allá de las fronteras provincianas. Quiero decir que el texto Papá murió hoy tiene posibilidades de ser leído en España y quizás en otros países hispanohablantes; posibi- 
lidades muy restringidas para las novelas y poemas que se editan en el Ecuador.

Elegí, pues, Papá murió hoy, de Telmo Herrera, por las circunstancias dichas, y sobre ese texto haré las consideraciones que siguen.

\section{Fisonomía DEL TEXTO}

Vamos a vérnoslas con un texto poético que es -0 pretende ser«relato», novela. No puedo evitar a este propósito unas palabras de Umberto Eco:

Nada consuela más al novelista que descubrir lecturas que no se le habían ocurrido y que los lectores le sugieren. Cuando escribía obras técnicas, mi actitud hacia los críticos era la del juez. ¿Han comprendido o no lo que quería decir? En el caso de una novela todo es distinto. No digo que el autor deba aceptar cualquier lectura, pero, si alguna le parece aberrante, tampoco debe salir a la palestra: en todo caso, que otros cojan el texto y la refuten. Por lo demás, la inmensa mayoría de las lecturas permite descubrir efectos de sentido en los que no se había pensado ${ }^{1}$.

Obviamente, no trato de plantear de entrada una autodefensa de mi análisis e interpretación frente al autor ni frente a otros analistas. Sólo quiero subrayar que entre las posibles lecturas, frente a las múltiples lecturas, he elegido aquella que me permita aproximarme lo mejor posible a lo que considero núcleo semiológico de este "poema» ${ }^{2}$.

\section{El texto-cuadro}

Entre las muchas preguntas que podemos hacernos para abordar el análisis, podemos elegir ésta: ¿cómo está planteado el «poema»? Podemos también dar una respuesta inicial: se trata de un diálogo del narrador consigo mismo y con unos interlocutores vivos y muertos. Expliquemos esto: el narrador lee «otro» texto, y ese otro texto es «la realidad percibi-

\footnotetext{
${ }^{1}$ Umberto Eco, Apostillas a «El nombre de la rosa», 2.a ed. (Barcelona: Lumen, 1985), p. 12.

${ }^{2}$ De alguna manera pretendo acercarme a ese «simulacro estético coherente dentro del espacio que permiten las ambigüedades más o menos intensas del lenguaje literario en cuestión» (cfr. Marcello Pagnini, Estructura literaria y método crítico [Madrid: Cátedra, 1975], p. 132).
} 
da» por él. Ahora bien, esa realidad percibida es la propia historia del narrador, o la propia historia del narrador tal y como se configura al ser percibida, al ser contada. La formulación de este diálogo resulta ser una especie de soliloquio muy particular: «Yo hablo conmigo mismo de esto que me pasó a mí.» «Esto que me pasó a mí, lo recuerdo ahora y lo escribo.»

El texto de Papá murió hoy está amasado con una serie de «otros» textos: las profesiones de fe del narrador; el tejido de las relaciones de parentesco; las anécdotas del pasado del narrador contadas por éste a los vivos y a los muertos; los cuentos de aparecidos y de miedo (hay al menos treinta y dos de ellos esparcidos a lo largo de las 192 páginas...).

Se trata, pues, de una serie de textos presentada en forma de collage, de retazos episódicos enunciados por el «narrador» en un soliloquio que a ratos, al evocar, por ejemplo, a un personaje de su infancia, se transforma en monólogo-con-el-otro. Por eso nos es imposible percibir una secuencia temporal: está todo ahí, como en un cuadro, simultáneamente, ante los ojos del «narrador»; o, mejor, ante su memoria, que se mueve libremente por el cuadro.

El interés particular que puede ofrecer esta obra es que no se trata de una novela al uso, con su historia y su argumento, con su discurso y su tema, con sus personajes y sus acciones, con su principio y su final. No es una historia: es una serie de recuerdos, casi todos de la niñez y de la adolescencia. No puede establecerse una secuencia temporal: es una yuxtaposición de cuadros sin conexión cronológica; una especie de enumeración caótica de recuerdos. No hay personajes propiamente dichos (personajes novelescos, se entiende): hay un narrador de una posible historia (posible historia "poemática», se entiende: porque hay una historia "real» como referente), y una serie de personajes insertos todos en el árbol genealógico del narrador, o afines a él por la amistad, o relacionados con él por la simpatía o la aversión. No hay acciones; hay recuerdos, nostalgias. No hay principio ni final: si nos atenemos a la pura manifestación del texto, podrían seguir otras 192 páginas, o $400 \ldots$ Opera aperta, en el sentido más rudimentario de este concepto.

\section{La función «fática»}

He dicho que la formalización de este diálogo es un soliloquio muy particular: «Esto que me pasó a mí, lo recuerdo ahora...» Pero enunciados como éste van muy frecuentemente seguidos de una muletilla: «iMe oyes?» Apenas hay una página del texto en la que no encontremos fórmulas de este tipo: 
¿Cuántas veces usted, Alfonsito, dio la vuelta al mundo como un astronauta? Sentado detrás de su máquina de coser cuero, como yo ahora detrás de mi máquina de escribir (p. 13).

Gracias, señor Andrade, gracias. Desde aquí, desde París, desde mi cuarto, mirando a la torre Eiffel, le digo gracias, muchas gracias (p. 30).

En el caso de nuestra primera cita el diálogo es con el tío Alfonsito, muerto hace algunos años:

Los muertos de mi familia. Mis muertos. Mis muertitos. Míos. Nadie me los puede quitar. Los llevo aquí, muy dentro del pecho. Muy dentro, como a usted, Alfonsito. Mi tío Alfonsito, el que murió esperando a la muerte, fumando un cigarrillo... (p. 131).

Debo subrayar que este diálogo, con apelación explícita al «interlocutor», no es solamente con las personas. También lo mantiene el «narrador» con los objetos y las cosas, especialmente con aquellos objetos que estuvieron cerca de él en su infancia:

Yo y mis primos, Faustino, Galo, Pepe, nos íbamos a coger sigses para hacer cometas y con un cochecito bajábamos por la cuesta que iba a la casa, no sé cómo nadie se rompió la pata en ese cochecito. Cochecito de mi infancia, un día te dedicaré un poema o un cuento (p. 100).

El «narrador» dedica largos espacios para conversar con «sus» muertos y contarles las cosas que sucedieron después de que los muertos murieran (véanse, por ejemplo, pp. 52-53).

A lo largo de este ensayo intentaré proyectar este rasgo de la fisonomía del texto sobre los ejes de la significación que considero medulares. Ya en esta breve presentación se echa de ver, en la pura estructura patente del texto, el objeto primorial de la función «fática» del lenguaje, tal como la definiera Jakobson:

Existen mensajes cuya función primordial es establecer, prolongar o interrumpir la comunicación, para comprobar si el canal funciona..., para atraer o confirmar la atención continua del interlocutor... Este «contacto», o «función fática»... se puede desplegar utilizando un profuso intercambio de fórmulas ritualizadas por diálogos complejos, con el simple propósito de prolongar la comunicación ${ }^{3}$.

${ }^{3}$ Roman Jakobson, «La lingüística poética», en Thomas A. Sebeok (ed.), Estilo del lenguaje (Madrid: Cátedra, 1974), p. 134. 
A partir, pues, de la hipótesis del texto-collage y de la manifiesta presencia de fórmulas «fáticas», puede iniciarse una búsqueda del sentido en el abigarrado y aparentemente caótico paisaje de la novela de Herrera.

\section{LAS OBSESIONES DE UN HUÉRFANO}

El narrador acaba de perder a su padre. Este acontecimiento parece ser el resorte inmediato que desencadena todo el discurso de Papá murió hoy. Pero mucho antes había excluido a Dios de su vida, y también había dejado fuera de ella la religión. De la religiosidad heredada y circundante sólo quedan, como residuos, ciertos comportamiento sociales, a los que aludiremos más adelante. Pero no es sólo la muerte del padre: a la luz de este suceso, el narrador evoca otras muchas muertes, todas de miembros de su familia. E1 lector podría pensar que se trata de un relato de muertes y de muertos. Pero no es así. Pienso que la pregunta radical que atraviesa el texto es ésta: «¿cómo trascender a la muerte? Y esta pregunta se constituye en una obsesión permanente. La cuestión planteada no tiene respuesta, ni el narrador puede encontrarla por más que la busque. Este, si no me equivoco, es el proceso:

\section{Familia sí, Dios no}

Curiosamente, junto a la profesión de increencia el narrador confiesa explícitamente su fe en la familia: "Yo no creo en Dios pero sí en las fiestas de familia, la unión hace la fuerza» (p. 53). Y páginas adelante:

Llegué a casa, bajé del auto y entré corriendo a botarme a los pies de mi mamá a pedirle su santa bendición de madre, no de Dios, en Dios no creo, en la familia sí, la unión hace la fuerza. Mi mamacita me dio la bendición, fue una ducha caída del cielo (p. 90).

Esta explícita negación de Dios se manifiesta a veces con ribetes grotescos y agresivos. El primo Galo, en travieso juego, lanza una bala en el interior de una plancha de carbón; la bala estalla y casi lo mata:

Y me contaba Pepe que decías casi agonizando: «Me muero, ya me estoy muriendo, traigan un cura para confesarme», y yo me reía porque, entre tú y yo habíamos hablado de Dios, habíamos dicho que no existe esa porquería, que es un invento de los políticos. Dios es un poder inventado por los hombres, habíamos dicho que la Biblia es el producto de unos excelentes poetas, artistas, que los apóstoles son unos 
buenos escritores y nada más y qué Dios ni qué pan caliente. Pero a la hora de sonar la bala, esa bala maldita que casi te mata, estuviste pidiendo un cura, «un hombre con faldas». ¡Cómo me reí! Bueno, primero tuve miedo de que te hubiese pasado algo serio, grave, pero luego, acordándome de lo del cura, me río hasta ahora. Sería el colmo que yo también, cuando me esté muriendo, pidiera un cura (pp. 110-111).

Si investigamos la fundamentación de una postura tan radical y explícita, apenas encontraremos en el texto un par de sugerencias muy próximas al tópico. No tenemos aquí una grave experiencia trágica, ni un planteamiento angustioso. Una de esas sugerencias nos remite al conocido planteamiento: no es posible que exista un Dios injusto:

... A mí también trataron de hacerme el mismo chiste, cuando tenía catorce años, porque un día, cuando estaba toda la familia reunida, pregunté si Dios estaba en todas partes y nos veía y me dijeron que sí, entonces yo metí el dedo largote de mi mano derecha en la boca, lo humedecí, lo saqué de mi boca y dando yuca dije que Dios se vaya a la mierda por ser tan cretino, por ayudar sólo a los ricos y a la policía (p. 134).

La otra sugerencia, más que referirse a la incredulidad o a justificarla, reproduce el conocido argumento de la Inquisición y sus atrocidades temerarias, para probar lo coherente de una postura al margen de la religión:

En Estrasburgo hay un puente desde el que, en la época de la Inquisición, a los culpables de brujerías u otras cosas, los lanzaban al río, encadenados y, para que se fueran hasta el fondo, les ponían una piedra de veinte kilos en los pies, los dejaban un ratito metidos en el río. Si las cadenas se liberaban y salían a flote, era una señal indiscutible del Señor, y si morían, si no salían a flote pues, simplemente eran culpables. Y si luego, algunos años después, se daban cuenta de que esa señora o de que ese joven o señor no había cometido ningún crimen, entonces decían que el Señor había querido llevarle a su santo seno para que no viviera entre tanta gente llena de tanta injusticia. Por eso, la religión, creo que es estúpida, primaria (pp. 139-140).

Dios y la religión quedan, pues, excluidos de la cosmovisión de este narrador sin más fundamento que el apuntado. Más parece que se asume la negativa como un postulado, sin entrar en honduras. Los planteamientos graves y las obsesionantes cuestiones tienen otras raíces; pero, como veremos, en última instancia nos remitirán a este punto de partida.

De la religiosidad heredada quedan ciertos residuos, también ciertas prácticas: la tía Domitilita «es mi madrina de bautizo y de confirmación» 
(p. 11). El propio narrador cuenta que su hermana Carmen y su cuñado Víctor, además de otros dos hijos, «tienen otra niña y yo seré el compadre de bautizo» (p. 82). Menciones de prácticas religiosas, de devociones populares, de rezos y ofrendas. El narrador las cuenta como parte del ambiente que lo rodeó durante su infancia y juventud. Pero de repente nos sorprende con pasajes como éste:

Nos paseábamos con Antonia por el barrio de Triana, el barrio de los comerciantes, donde los que partían para América compraban vino, jamón y tantos otros productos. En el muelle se despedían de sus familias y novias y de una virgencita que todavía está allí, antes de pasar el Puente de Triana. Y yo, cada vez que voy a Sevilla, voy a visitarla, y hago el mismo gesto, me persigno aunque no creo en Dios (p. 60).

El detalle no carece de importancia. Esta aparente contradicción refleja un mundo interior ambiguo, vacilante, al que dedicaremos algunas consideraciones en la parte final de este estudio.

Aparejada con esta profesión de incredulidad va la profesión de fe en la familia: lo que es, lo que tiene la familia, es también la fundamentación del ser y del vivir del narrador. En algún momento se entretiene en presentarnos una genealogía que arranca de 1560 y llega hasta el presente (véanse pp. 127-128); y muy especialmente se preocupa de subrayar la importancia de la madre en el hogar:

La madre es el centro del hogar; el hombre, el papá, es un ser de paso. Cuando es la mamá la que se muere en un hogar, todo se va a la mierda. Todo. Nosotros gravitamos alrededor de la mamá, de la abuela, no del padre (p. 177).

$\mathrm{Y}$ ante la muerte de un familiar, las imágenes que usa son como éstas: «... era una tristeza de niño abandonado, era como si el círculo familiar se hubiera roto y que por un hueco, el del muerto, se escapara algo vital, la vida misma» (p. 70; los subrayados son míos).

\section{... Se van muriendo...}

Decía que el relato resultaba de una cuestión radical: ¿cómo trascender a la muerte? El perpetuarse en el frondoso árbol genealógico, en las relaciones de amor, parecía constituir una primera respuesta. En ella estaban incluidos los amigos. Pero esta respuesta no satisface la inquietud radical planteada: «Y mis amigos se van muriendo. Mi familia también 
se va muriendo. Sentido pésame, doblar la página y a seguir caminando.» Son las palabras iniciales del texto (p. 9). «Y mis amigos se van muriendo. Nosotros, poquito a poquito, también» (p. 31). «Mis amigos han desaparecido del mapa» (p. 176). Pero no sólo mueren familiares y amigos, también va muriendo el «entorno» de la niñez y de la adolescencia del narrador: «... Para mí, cada casa destruida es un cementerio, cada familia que se ha ido es un cementerio, esa gente que ya no volverá es un cementerio» (p. 185).

El viento del pueblo de Atahualpa, ya no es el mismo. A lo lejos se oye una rocola y no los acordes de una guitarra con sus vísceras careadas. El guagua mishque (el hijo del diablo) ya no llora en las noches de luna ni en las noches de tinieblas. Y los viejecitos y la verdadera historia de un pueblo, el espíritu que lo anima, se van muriendo igual que los árboles enfermos, como el árbol de aguacate, más que centenario de mi tía Guillermita en el patio inmenso de su casa, realmente inmenso (p. 36).

Es significativa la insistencia en recalcar esta progresiva desaparición de todos y de todo: "Están desapareciendo los payasos y es una pena...» (p. 45). «Las fiestas del Año Viejo, laș fiestas del niñito Jesús, todo eso ya no existe» (p. 132). «Todo en la Vicentina, mi barrio, mi querido barrio, desaparece, todo, no es ningún cuento, ni literatura» (p. 159). «Las cantinas del barrio La Vicentina, también han desaparecido» (p. 168). "Ahora ya no queda nada, puro cemento como tumbas» (p. 172).

La evocación nostálgica de las cosas que fueron es una especie de leitmotiv en nuestro texto:

Ya no existe el jardín de mi casa, ya no hay flores en mi casa, ya no hay esas lindas flores que sembraban mis tías. Ya no existen los huecos, junto al servicio higiénico donde jugábamos a los güevos de gato con los hijos del Enriquito. Ya no existe la tapia donde lloraban los gatos (p. 100).

El narrador se rebela porque hasta los enemigos van muriendo: "Y ya no hay nada que hacer, si hasta esos sinverguienzas desaparecen, si hasta esos canallas abandonan la tierra, nuestros seres queridos también, todo desaparece, todo cambia, se transforma» (p. 186).

$Y$ es consciente de que también a él le atañe el asunto, y muy de cerca; por eso una de sus primeras reacciones es la huida:

Yo huyo de la muerte, más que del diablo; creo que con el diablo se puede dialogar, es muy inteligente el diablo católico, pero con la muerte, ni hablar; negra, toda negra como los curas (p. 122). 
En todo caso, porque sabe que es irremediable, se enfrenta con ella; pero no con sumisa resignación, sino con agresiva arrogancia:

Yo también me daré una cita con la muerie el día que yo quiera, el día que yo decida. La muerte no tiene por qué decidir por mí, yo nunca he tenido ningún patrón (los patrones han terminado siendo mis amigos), ningún pendejo me ha mandado, me ha dado órdenes. La muerte tampoco tiene por qué venir a darme órdenes, venir a joderme. Yo la llamaré cuando yo quiera, cuando yo tenga ese deseo sensual de morir, como cuando yo salgo en busca de una mujer, y quien busca encuentra. Así, muerte mía, yo te buscaré. Tal vez en el poste de una esquina, de la propia esquina de mi barrio (p. 133).

\section{Rebelión contra la muerte}

Considero fuera de toda duda que nuestro personaje, al hacer su opción fundamental de negar toda trascendencia, una opción que en principio podía parecernos ligera y sin fundamento, ha dado en el blanco al tropezarse con la muerte como el único obstáculo capaz de hacerlo ir al fondo de las cosas. Y como es el único obstáculo, intenta arremeter contra él para ver si puede vencerlo: "Yo quería agarrar a la muerte y patearla a mansalva, sin compasión, que no nos jodiera más. Y nos sigue jodiendo...» (pp. 42-43). Al recibir el telegrama que da título a la obra, nos dice, «mis ojos se volvieron rojos de cólera contra la muerte» (p. 75).

$\mathrm{Y}$ ese intento lo lleva hasta los límites del paroxismo:

Y no, no es así, cuando un nuevo muerto llega te vuelves con el dolor un látigo golpeando alfombras y qué ganas de agarrarse uno mismo como una piedra y lanzarse lejos, muy lejos y cuando regresamos a ver, nosotros mismos darnos un piedrazo y rompernos como un espejo y sobre esos vidrios rotos, bailar, bailar, gritar como un endemoniado ensangrentando los pies y, con esa sangre y nuestros propios cabellos, hacer una brocha para ir pintando todos los cementerios de rojo, que el color negro de la muerte no vuelva más. Carajo, que no vuelva más. iNunca más! (p. 67; véanse también pp. 9, 56, 156).

\section{¿Cómo trascender la muerte?}

El narrador, sin dejar de lado un solo momento la rebeldía, intenta modos de trascender la muerte. En la infancia lo hace por medios mágicos. En una de las historias fantásticas, contada como autobiográfica en primera persona, nos dice: 
... Decían que allí, contra el muro de la colina, había sido aplastado un señor por una volqueta y que en ese hueco habia que lanzar tres piedritas y lanzar también una oración por la salvación del alma del muerto... A veces yo tenía que pasar solito con mis cuadernos delante del hueco del muerto, lanzaba mis tres piedritas, rezaba rapidito una oración y me iba corriendo cuesta abajo, sin regresar a ver. Un buen día maté al muerto, agarré una piedra grandota, apunté bien, imitando a un beisbolista, y lancé la piedra, la cruz cayó de espaldas y todas las piedritas que rodeaban la cruz terminaron por sepultar la cruz. Desde ese día perdí el miedo de pasar delante del hueco del muerto (pp. 26-27).

Más que superación de la muerte es, evidentemente, superación del miedo; también hay un símbolo de la opción fundamental a la que hemos aludido: no sólo «maté al muerto», sino que también «todas las piedritas que rodeaban la cruz terminaron por sepultar la cruz». Sin embargo, leemos con cierta frecuencia en el texto que el miedo no ha desaparecido del todo: "Hoy lo escribo, son las cuatro de la mañana, y en verdad que tengo miedo todavia, y tengo treinta y seis años; esta mañana, en mi dormitorio, se rompió un vidrio, se cayó, así, solito, ¿presentimiento? Apunto» (p. 39). Es, una vez más, la ambigüedad, a la que también hemos aludido.

Otro modo ilusorio de trascender la muerte es la recuperación de los objetos familiares, esos objetos que forman parte de la vida:

Quiero recuperar todo lo que perteneció a los Herrera, antes de que esos hermosos objetos terminen en la basura o sean cambiados por un mueble de plástico o una televisión. El clarinete de mi abuelo, un clarinete hermoso, de plata, que estuvo en sus manos durante cuarenta años, que estuvo entre sus labios, en sus rodillas, junto a la cama, un clarinete frío pero que se calentaba con la sangre caliente de mi abuelo, to tengo yo, forma parte de las reliquias sagradas de nuestra familia (p. 37).

También es un intento de trascender la muerte la recuperación de la historia familiar por fotografías y transmisión de nombres:

Al único cura que yo quería, era a mi tío el Padre Telmo, un cura muy inteligente. El nos tomó casi a todos las fotos que tenemos en la familia. Puedo reconstruir toda la vida de los Herrera, gracias a esas fotos, las fotos que nos tomaba el Padre Telmo. Lloré de rabia cuando murió (p. 111).

Mercedes se casó con Oswaldo, machacheño. Ella, ahí, en ese pueblo, es profesora, tiene dos hijos, Telmo Oswaldo y María Augusta, mis dos nombres reunidos (p. 53). 
Enriquito, si algún día tengo un hijo, tendrá su nombre, en su honor y en el de papá, se llamará Telmo Enrique (p. 104).

El diálogo con los muertos, al que aludí al comentar la persistente presencia de la «función fática» del lenguaje, es otro modo de traspasar esta barrera insalvable de la muerte. No deja de ser significativo cierto aire de humor irónico en este pasaje, en el que el narrador dialoga con el difunto primo Mario:

Mario, verás, te cuento, tú eras el tercer muerto de la familia, muertos que yo vi, quiero decir, después del Niquito y de mi hermanito, así que te voy a contar.

Muchos ya no están, mi papacito por ejemplo, a quien tú querías tanto, búscale por ahí, en el mundo de los muertos, él también te está buscando, busca en el anuario telefónico de las almas que se van, y sabes, envíame a mí el número (p. 52).

El recuerdo es obviamente otro modo de mantener la presencia de la vida, la presencia de la familia. El narrador se aferra a la memoria de los muertos en un intento de seguir con ellos en la vida:

Los muertos de mi familia. Mis muertos. Mis muertitos. Míos. Nadie me los puede quitar. Los 1levo aquí, muy dentro del pecho. Muy dentro, como a usted, Alfonsito. Mi tío Alfonsito, el que murió esperando a la muerte, fumando un cigarrillo... (p. 131).

Enriquito era muy serio (es, porque sigue en mi recuerdo), casi nunca hablaba, se pasaba el tiempo leyendo, mirando cosas lejanas (p. 103).

Finalmente, 1a escritura. Decía André Malraux: «Yo estoy persuadido de que el proceso creador, en el novelista, está ligado a la naturaleza del pasado que le habita o que le huye» ${ }^{4}$. En esta historia el pasado es un presente que actúa paradójicamente sobre el narrador. En algún momento se pregunta para qué escribir, si la familia era el único objeto de sus poemas, el único auditorio:

¿A quién voy a leer ahora los cuentos?, ¿a quién mis poemas, mis obras de teatro? ¿A quién? Sé, que todavía existe la familia, que es para ellos lo que escribo (p. 113).

\footnotetext{
"André Malraux, citado por Charles Moeller en Literatura del siglo XX y cristianismo, tomo IV, p. 185.
} 
La escritura, con todo, será una manera de hacer presente el pasado. Será un modo de trascender el mismo presente:

Lindos juegos de infancia y de adolescentes que se van yendo, desapareciendo, ventajosamente escribo, mis sobrinos leerán mis picardias, aunque ellos no necesiten que yo les enseñe, ellos, solitos, por instinto, aprenderán, así es la vida, así es (p. 39).

Yo, aquí, Guillermito, en París, recordando su voz, recordando a mis muertos, solo, yo, el recuerdo y mi máquina de escribir (p. 63).

Ahora tengo miedo del recuerdo, de que todo se borre, por eso escribo al tío Carlos, enterrado en el Cementerio de Atahualpa (p. 35).

La escritura: he aquí el recurso último, el único que le queda a este personaje-narrador para trascender lo que es inexplicable e intraspasable sin la aceptación, sin la incorporación de la trascendencia a la vida:

... Y si no estuviera yo para contarlo, nadie se acordaría ... La escritura es la magia del Universo, lo más colosal que el hombre ha inventado. Después del fuego, la escritura. Yo me acuerdo y puedo escribir, y escribiendo, cuento lo que vi, nada de lo que aquí digo es cuento chino, nada, todo existió (p. 179).

\section{REFLEXIÓN FINAL}

La preocupación radical de nuestro personaje-narrador es cómo trascender el tiempo, cómo superar lo inevitable: el término del tiempo, el final de la vida, cómo «matar la muerte». Pienso que uno de los ejes semánticos fundamentales del texto es el eje eternidad/temporalidad. La consideración de la fisonomía del texto ya nos sugería este carácter definitorio: se trata, dijimos, de un texto-collage en el que todo está presente, en el que no hay secuencia temporal. Es que el narrador está en una situación peculiar: por una parte existe el hecho de que «todo pasa»; y, por otra, no se quiere que pase. En definitiva, se quiere afirmar la eternidad entendida como aspiración radical, no de negar el tiempo, sino de trascenderlo: de negar su división en momentos. Por eso el collage: no pasó esto primero, y pasó; y esto segundo (y posterior a lo primero) y pasó. No: Yo quiero trascender eso, parece decirnos el narrador, y por eso «lo cuento» así: no puedo prescindir del carácter lineal del lenguaje, y por ello hago de él una especie de línea espiral, de manera que al menos tenga la ilusión de decirlo todo «a un tiempo»; de manera que mi interlocutor tenga ante sí -ilusoriamente- un «cuadro» total y como simultáneo. Por eso la 
continua utilización de la función fática del lenguaje. Por eso la ausencia de «final»: este texto no puede tener desenlace, no puede terminar. Un curioso intento poético de realizar la definición boeciana de eternidad: «interminabilis vitae...»P Pero un intento que excluye, de entrada, la fundamentación trascendente, al excluir precisamente a quien trasciende el antes y el después; es decir, a quien trasciende el tiempo.

En el texto de Papá murió hoy la nostalgia del "pasado» es persistente. Se lamenta el «cambio» de las cosas, de la vida. Ahora bien, la pena de que las cosas hayan cambiado de "entonces» a «hoy" no es mera expresión de que todo tiempo pasado fue mejor. Es precisamente la obsesión (contrapunteada por la impotencia) por la inmutabilidad: no deberían cambiar las cosas, no deberían desaparecer los seres queridos que significaban, por así decir, la «plenitud», la «perfecta vitae possessio» boeciana. En aquellas anécdotas de la infancia y de la juventud que el narrador evoca en el movimiento de la enunciación tuvo él la vivencia plena de la vida. Y ésa es su desesperante y suprema ansiedad: que aquello no pasara (es decir, que no se constituyera en pasado). La realidad es que pasó. Y esto lo subleva. El narrador, que ha desplazado a Dios, busca revelarlo, y encuentra como principal relevo el entramado familiar («la unión hace la fuerza»); me pregunto si también será esto una ilusión. ¿No será él mismo el relevo? En todo caso, el enemigo radical de esa fuerza se hace presente: la muerte. Es lo único incontrovertible, inmutable, cuando Dios ha desaparecido de la escena. Las propias palabras del narrador resultan el más elocuente argumento de esta aseveración y al mismo tiempo reflejan con dramatismo el interrogante y la duda que no han logrado desvanecerse:

Solo los muertos, las cosas no cambian, quedan ahí, estáticos, los llevamos para siempre con nosotros, o quién sabe, puede que hasta allá en el Imperio de los muertos, los muertos también cambien. Las cosas son frescas, parecen inmortales, y lo son, instantáneamente (página 188). 
